\title{
The Pyridine-nucleotide Transhydrogenase of Salmonella typhimurium
}

\author{
By A. P. SINGH AND P. D. BRAGG \\ Department of Biochemistry, University of British Columbia, \\ Vancouver 8, Canada
}

(Received 15 October 1973; revised Io December 1973)

SUMMARY

Energy-dependent and energy-independent transhydrogenase activities in the membrane particle fraction from Salmonella typhimurium were less markedly repressed by amino acids than in Escherichia coli. Energy-dependent transhydrogenation of NADP+ by NADH was driven either by energy from NADH oxidation through the respiratory chain, or from ATP, GTP or ITP but not by CTP, UTP, ADP and adenosine monophosphates. Adenosine monophosphates had little effect on ATP-driven and energy-independent reactions but 5'-AMP and $3^{\prime}, 5^{\prime}$-AMP, like cyanide and sulphide, inhibited the aerobic-driven reaction via an inhibitory effect on the respiratory chain of the organism. Dicyclohexylcarbodi-imide and phosphate inhibited the use of ATP as an energy donor, while carbonyl cyanide- $m$-chlorophenylhydrazone discharged the energized state required for energy-dependent transhydrogenation. Washing removed proteins needed for both energy-dependent activities but not for the energy-independent reaction. Re-addition of the 'coupling factor' restored the lost activities fully. Coupling factor preparations from this organism and from E. coli were interchangeable.

\section{INTRODUCTION}

Mutants of Escherichia coli and Salmonella typhimurium have recently been isolated with impaired ability to transport amino acids (Simoni \& Shallenberger, 1972; Hong \& Kaback, 1972) and to carry out the energy-dependent transhydrogenation of NADP+ by NADH (Bragg \& Hou, 1973; Bragg and Hou, unpublished). Furthermore, $N, N^{\prime}$-dicyclohexylcarbodi-imide (DCCD) which can stabilize the energized state* required for the aerobicdriven energy-dependent transhydrogenation (Bragg \& Hou, 1973) can also stabilize the energized state used in amino acid transport (B. P. Rosen, personal communication). These findings suggest that the same energized state is used both for active transport of amino acids and for energy-dependent transhydrogenation.

While continuous measurements of amino acid uptake cannot conveniently be carried out, the reduction of pyridine nucleotide can be more readily followed and can be used to study the kinetics of formation of the energized state. Whether ATP is employed as an energy source for amino acid transport also cannot be directly examined since the cell membrane is impermeable to this nucleotide. However, since the respiratory particles used in transhydrogenation studies are inverted ('inside out'), it is possible to study the energization process using either ATP (ATP-driven transhydrogenase), or energy derived by

* This term is used to describe the immediate driving force for energy-dependent transhydrogenation or transport of amino acids, but without implying what its exact nature (chemical intermediate, conformational state, proton gradient, etc.) might be. 
oxidation of substrate via the respiratory chain (aerobic-driven transhydrogenase). The transhydrogenase enzyme itself can be examined independently of the energization process by measuring the reduction of $\mathrm{NAD}^{+}$(or 3-acetylpyridine-NAD ${ }^{+}$) by NADPH (energyindependent transhydrogenase). The transhydrogenation reaction in this direction does not require an energy source. Studies with mitochondria (Kawasaki, Satoh \& Kaplan, 1964; Lee, Simard-Duquesne, Ernster \& Hoberman, 1965) suggest that the same enzyme is involved in both the energy-independent and the energy-dependent transhydrogenase reactions. The transhydrogenase' system would thus appear to be ideal for studies of the formation and properties of the energized state.

Although Escherichia coli has been used for many transport studies it cannot utilize citrate, and while Salmonella typhimurium is suitable for such studies, little is known about the energization process in this organism or the action of inhibitors on it (Imai, Iijima \& Hasegawa, I973). In collaboration with Dr W. W. Kay (University of Saskatchewan), mutants of $S$. typhimurium have been isolated with impaired citrate transport and with defects in the energization process. Before using the transhydrogenase system in our studies with these mutants we characterized this system more fully, particularly with regard to the action of inhibitors. Although the action of inhibitors on the ATP-driven and energyindependent transhydrogenase systems of $E$. coli has been studied (Bragg \& Hou, I968; Sweetman \& Griffiths, 1971), little is known about their site of action on the aerobic-driven transhydrogenase system.

Furthermore, in preliminary studies of the effect of amino acids in the growth medium of Salmonella typhimurium on the formation of its transhydrogenase system, we observed that the energy-dependent transhydrogenase was not repressed as completely as was that of Escherichia coli (Bragg, Davies \& Hou, 1972). We therefore wished to compare the transhydrogenase systems of the two organisms to determine whether they were significantly different.

\section{METHODS}

Chemicals. ATP, 5'-AMP, 3',5'-AMP, CTP, GTP, ITP, UTP, NAD + , NADH, NADP + , NADPH, alcohol dehydrogenase (yeast), dicumarol, L-3,3',5-tri-iodothyronine and bovine serum albumin (BSA) were purchased from Calbiochem. 2'-AMP, 3-acetylpyridine-NAD ${ }^{+}$, 3-acetylpyridine-NADP ${ }^{+}$and dithiothreitol (DTT) were obtained from Sigma. $3^{\prime}$-AMP, desamino-NAD ${ }^{+}$and carbonyl cyanide- $m$-chlorophenylhydrazone (CCCP) were products of Schwarz Bioresearch (New York), P-L Biochemicals (Milwaukee, Wisconsin) and E. I. Du Pont de Nemours (Wilmington, Delaware, U.S.A.) respectively.

Bacterial strains. Salmonella typhimurium LT2 and Escherichia coli ML308-225 were used in all experiments.

Media and growth. Minimal salts-glucose medium containing $12 \mu \mathrm{M}$-ferric citrate (Bragg et al. 1972), or $0.8 \%$ Bacto-nutrient broth (Difco) containing $0.3 \%$ Bacto-yeast extract (Difco) (NBYE), or trypticase soy (TS) medium (BBL) were used. Bacteria were grown at $37{ }^{\circ} \mathrm{C}$ with aeration on a reciprocating water bath shaker. As inoculum, $0.4 \%(\mathrm{v} / \mathrm{v})$ of an overnight culture grown in the same medium was used. For large-scale production of organisms, a $10 \%(\mathrm{v} / \mathrm{v})$ inoculum was used and the cultures were incubated at $37^{\circ} \mathrm{C}$ with vigorous aeration from a sparger. Results are given for organisms grown on a minimal salts-glucose medium, unless otherwise indicated.

Preparation of membrane particles, stripped membrane, and coupling factor. These were prepared as previously described for E. coli (Bragg et al. 1972; Bragg \& Hou, 1972).

Enzyme assays. Energy-dependent (aerobic- and ATP-driven) transhydrogenase was 
Table I. Specific activities of transhydrogenases of particulate fractions from E. coli and S. typhimurium

$\begin{array}{llccc}\text { Organism } & \begin{array}{l}\text { Growth } \\ \text { medium* }\end{array} & \text { Independent } \dagger & \begin{array}{c}\text { Aerobic- } \\ \text { driven } \dagger\end{array} & \text { ATP-driven } \dagger \\ \text { E. coli } & \text { SG } & 228(100) & 42 \cdot 6(100) & 39 \cdot 0(100) \\ & \text { TS } & 112(49) & 3 \cdot 7(9) & 11 \cdot 6(30) \\ & \text { NBYE } & 100(44) & 0(0) & 8 \cdot 1(21) \\ \text { S. typhimurium } & \text { SG } & 265(100) & 24 \cdot 1(100) & 28 \cdot 5(100) \\ & \text { TS } & \text { I4I (53) } & 17 \cdot 6(73) & 18 \cdot 9(66) \\ & \text { NBYE } & 91(34) & 9 \cdot 0(37) & 14 \cdot 6(51)\end{array}$

* SG, salts-glucose medium; TS, trypticase-soy medium; NBYE, nutrient broth-yeast extract medium. $\dagger$ Percentages are given in brackets.

measured by a slight modification of the method of Fisher \& Sanadi (I97I) as described by Bragg et al. (1972). Assay of energy-independent transhydrogenase, which was based on the method of Kaplan (1967), was carried out at $37^{\circ} \mathrm{C}$ in a reaction mixture containing $50 \mathrm{mM}$-phosphate buffer, $\mathrm{pH} 7.0,250 \mu \mathrm{g}$ membrane particles, I.0 mM-3-acetylpyridine$\mathrm{NAD}^{+}$and $0.5 \mathrm{~mm}$-NADPH in a total volume of $\mathrm{I} .0 \mathrm{ml}$. The reduction of 3-acetylpyridine$\mathrm{NAD}^{+}$was measured at $375 \mathrm{~nm}$, using a Coleman 124 spectrophotometer.

NADH oxidase was determined spectrophotometrically by following the decrease in absorbancy at $340 \mathrm{~nm}$ of a medium containing, in a total volume of $1.2 \mathrm{ml}: 0.15 \mathrm{~mm}-$ $\mathrm{NADH}, 50 \mathrm{~mm}$-tris-HCl buffer ( $\mathrm{pH} 7 \cdot 8$ ), and 150 to $200 \mu \mathrm{g}$ membrane particles. Protein was determined by the method of Lowry, Rosebrough, Farr \& Randall (I95I).

In all instances, one unit of enzyme activity represented the conversion of one nanomole of substrate or product per minute.

\section{RESULTS AND DISCUSSION}

As with Escherichia coli (Bragg \& Hou, I968; Fisher \& Sanadi, I97I; Sweetman \& Griffiths, I97I) and the mammalian mitochondrion (Kawasaki et al. I964; Lee et al. 1965), the membrane-bound transhydrogenase of Salmonella typhimurium catalysed the reduction of (i) NADP+ by $\mathrm{NADH}$, (ii) the reduction of either $\mathrm{NAD}^{+}$or 3-acetylpyridine-NAD ${ }^{+}$ by NADPH. Reaction (i) required energy which could be generated either by oxidation of NADH through the respiratory chain of the organism (aerobic-driven transhydrogenase) or by ATP hydrolysis (ATP-driven transhydrogenase). Reaction (ii) (energy-independent transhydrogenase) did not display a requirement for an energy source.

The effect of various growth media on the formation of energy-dependent and energyindependent transhydrogenase activities in Escherichia coli and Salmonella typhimurium are shown in Table 1 . In the presence of amino acids the activity of the energy-independent transhydrogenase was depressed by about 50 to $65 \%$ in both organisms. A more striking difference was observed in the case of the energy-dependent reactions. Whereas the loss of energy-dependent transhydrogenase activities in $S$. typhimurium approximately correlated with the loss of the energy-independent activity, the loss of the energy-dependent activities was much greater in $E$. coli.

Because of the above differences between the transhydrogenase systems of the two organisms, the specificity of the transhydrogenase system of Salmonella typhimurium for electron donor and acceptor, and for energy donor, were examined. As with Escherichia coli (Sweetman \& Griffiths, 1971), NADH was the most effective electron donor for the reduction of 
Table 2. Specificity of energy-independent transhydrogenase of S. typhimurium for electron acceptor* and of ATP-driven transhydrogenase for electron donor $\dagger$

\begin{tabular}{|c|c|c|c|c|}
\hline $\begin{array}{l}\text { Direction of hydrogen } \\
\text { transfer }\end{array}$ & $\begin{array}{l}\text { Energy } \\
\text { source }\end{array}$ & Acceptor or donor & $\begin{array}{l}\text { Concentra- } \\
\text { tion } \\
\text { (mM) }\end{array}$ & $\begin{array}{l}\text { Specific } \\
\text { activity }\end{array}$ \\
\hline \multirow[t]{3}{*}{ NADPH to acceptor } & None & $\mathrm{NAD}^{+}$ & $\begin{array}{l}0.2 \\
0.4 \\
0.8\end{array}$ & $\begin{array}{l}29 \cdot 8 \\
34 \cdot 0 \\
41 \cdot 0\end{array}$ \\
\hline & & Thio-NAD ${ }^{+}$ & 0.15 & 0 \\
\hline & & 3-Acetylpyridine-NAD ${ }^{+}$ & $\begin{array}{l}0.3 \\
0.15 \\
0.3 \\
0.6\end{array}$ & $\begin{array}{c}0 \\
76 \cdot 1 \\
96 \cdot 8 \\
100\end{array}$ \\
\hline Donor to NADP+ & ATP & $\begin{array}{l}\text { NADH } \\
\text { Desamino-NADH } \\
\text { 3-Acetylpyridine-NADH }\end{array}$ & $\begin{array}{l}0.075 \\
0.075 \\
0.075\end{array}$ & $\begin{array}{r}25 \cdot 4 \\
4 \cdot 6 \\
5 \cdot 2\end{array}$ \\
\hline
\end{tabular}

* The standard assay was used in all cases except that 3-acetylpyridine-NAD ${ }^{+}$was replaced by the electron acceptor indicated. The reduction of thio-NAD ${ }^{+}$was followed at $400 \mathrm{~nm}$ (extinction coefficient, II $3 \mathrm{~mm}^{-1}$ ). With $\mathrm{NAD}^{+}$transhydrogenase activity was measured by following the oxidation of NADPH at $340 \mathrm{~nm}$.

$\dagger$ The standard assay was used but with $\mathrm{NAD}^{+}$being replaced by the compounds indicated.

$\mathrm{NADP}^{+}$in the energy-dependent transhydrogenase reactions. Desamino-NADH and 3 -acetylpyridine-NADH were only to to $20 \%$ as effective as NADH (Table 2). This was not due to the specificity of the alcohol dehydrogenase used to generate the reduced nucleotide. By contrast, the energy-independent transhydrogenation of NAD ${ }^{+}$by NADPH was $40 \%$ as active as the reduction of 3-acetylpyridine-NAD ${ }^{+}$(Table 2). Although the specificity of the energy-independent transhydrogenase of $S$. typhimurium for thio-NAD ${ }^{+}$and 3-acetylpyridine-NAD ${ }^{+}$as electron acceptor was the same as that of $E$. coli (Sweetman \& Griffiths, 1971 ; Singh and Bragg, unpublished results), it differed from that of Pseudomonas aeruginosa (Cohen \& Kaplan, 1970) and Azotobacter vinelandii (Chung, 1970; Van den Broek, Santema, Wassink \& Veeger, 197I). In the last two organisms the reduction of thio-NAD ${ }^{+}$with NADPH occurs readily. This nucleotide was not reduced by the $S$. typhimurium system where 3-acetylpyridine-NAD ${ }^{+}$was the most active electron acceptor. 3-Acetylpyridine-NAD ${ }^{+}$is not reduced by the enzyme from $A$. vinelandii.

In agreement with the findings of Sweetman \& Griffiths (197I) for Escherichia coli, the ATP-dependent transhydrogenation of $\mathrm{NADP}^{+}$by NADH in Salmonella typhimurium could be supported by ATP, GTP and ITP and the amount of NADP+ reduced in the presence of these compounds was 29,24 and $17 \mathrm{nmol} / \mathrm{min} / \mathrm{mg}$ protein, respectively. CTP, UTP, ADP, or $2^{\prime}-, 3^{\prime}-$ or $3^{\prime}, 5^{\prime}$-AMP did not act as energy donors. The effectiveness of the triphosphates as energy donors is probably related to the specificity of the membranebound ATPase (Davies \& Bragg, 1972) which in $E$. coli has been shown to be involved in the ATP-driven transhydrogenase reaction (Bragg \& Hou, 1972).

Both the aerobic- and ATP-driven transhydrogenase reactions were stimulated by $\mathrm{Mg}^{2+}$ in Salmonella typhimurium (Fig. I) whereas in E. coli the latter reaction did not depend on $\mathrm{Mg}^{2+}$ (Sweetman \& Griffiths, 197I). The $K_{m}$ for ATP in the ATP-driven transhydrogenase, as calculated from a Lineweaver-Burk plot of the data shown in Fig. I, was 0.I4 mM. This is comparable to the value of $0.28 \mathrm{~mm}$ found for Escherichia coli (Sweetman \& Griffiths, 197I).

In contrast to the soluble transhydrogenases of Azotobacter vinelandii (Chung, 1970) 


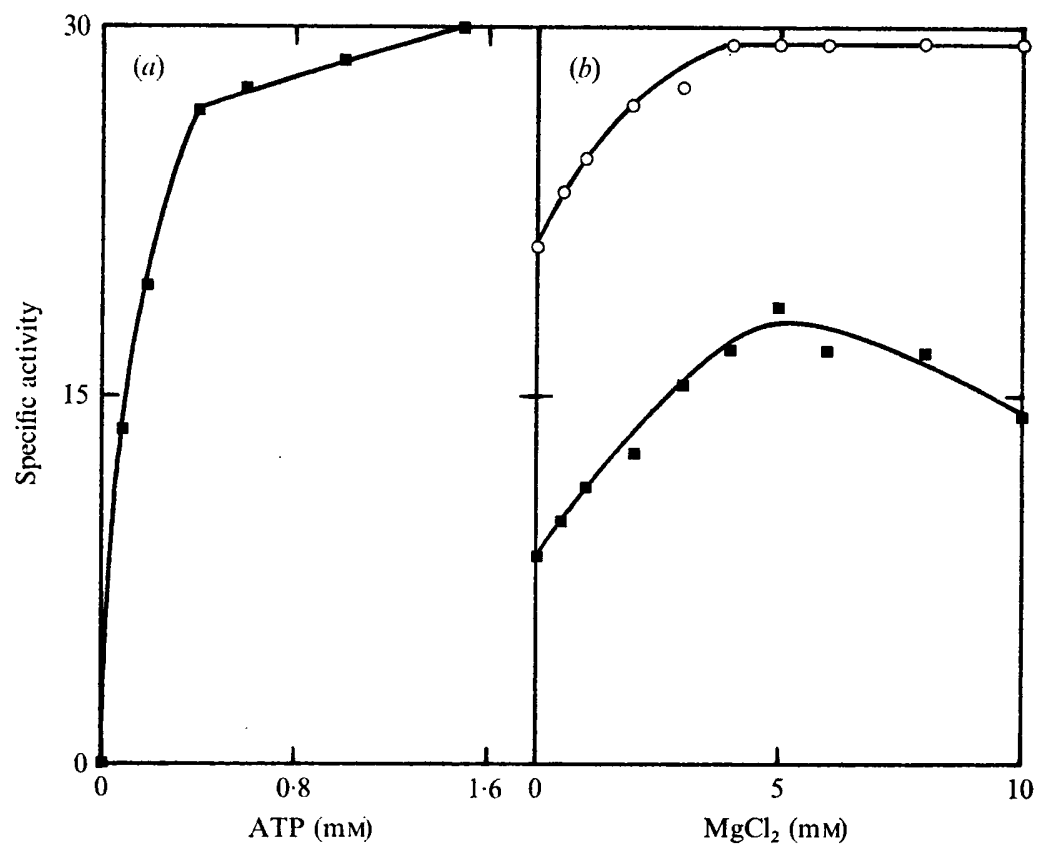

Fig. I. Effect of ATP (a) and $\mathrm{MgCl}_{2}$ (b) concentrations on the aerobic- (o) and ATP-driven (a) transhydrogenase activities of the particulate fraction from $S$. typhimurium. The concentrations of $\mathrm{MgCl}_{2}$ and ATP in (a) and (b) were $5 \mathrm{mM}$ and $0.5 \mathrm{mM}$, respectively. Particulate fraction: (a), $1.5 \mathrm{mg}$ protein; $(b), 0.68 \mathrm{mg}$ protein.

and Pseudomonas aeruginosa (Cohen \& Kaplan, 1970), and the membrane-bound enzyme of the mammalian mitochondrion (Rydström, I972), 2'- and $3^{\prime}$-AMP had little effect on the energy-dependent or energy-independent transhydrogenase activities of Salmonella typhimurium (Fig. 2). Although $5^{\prime}$-AMP was an effective inhibitor of the aerobic-driven reaction with $\mathrm{NADH}$ as electron donor, the action of this nucleotide was apparently not on the transhydrogenase itself but was on the oxidation of NADH by the respiratory chain (Fig. 2). Although the rate of transhydrogenation was inhibited, there was no change in the efficiency with which this occurred. NADPH:O ratios (0.20) (Bragg et al. 1972) showed a Io to $15 \%$ increase in the presence of 2 mM- 5 -AMP. Thus, inhibition of the aerobic-driven transhydrogenation of NADP + by NADH was probably due to a slowing of the respiratory chain by $5^{\prime}$ - and $3^{\prime}, 5^{\prime}$-AMP and hence to a decrease in the rate at which aerobicallygenerated energy could be supplied to the transhydrogenase.

The effect of the various adenosine monophosphates on the transhydrogenase and NADH oxidase activities of Escherichia coli was exactly the same as that found with Salmonella typhimurium. ADP (6 mM) had no effect on either the transhydrogenase or NADH oxidase activities in both organisms. These results are not in agreement with the findings of Worcel \& Goldman (1964) and Revsin \& Brodie (1967) who found that ADP and $5^{\prime}$-AMP stimulated NADH oxidase activity in Mycobacterium spp.

The effect of other inhibitors on the energy-independent, aerobic- and ATP-driven transhydrogenase activities of Salmonella typhimurium is shown in Table 3, and their sites of action are indicated in Fig. 3. The energized state $(\sim)$ is generated at one or more sites along the respiratory chain during the oxidation of NADH (Fig. 3). This state may also be generated from ATP, the $\mathrm{Ca}^{2+}$-, $\mathrm{Mg}^{2+}$-activated ATPase being involved in this process 


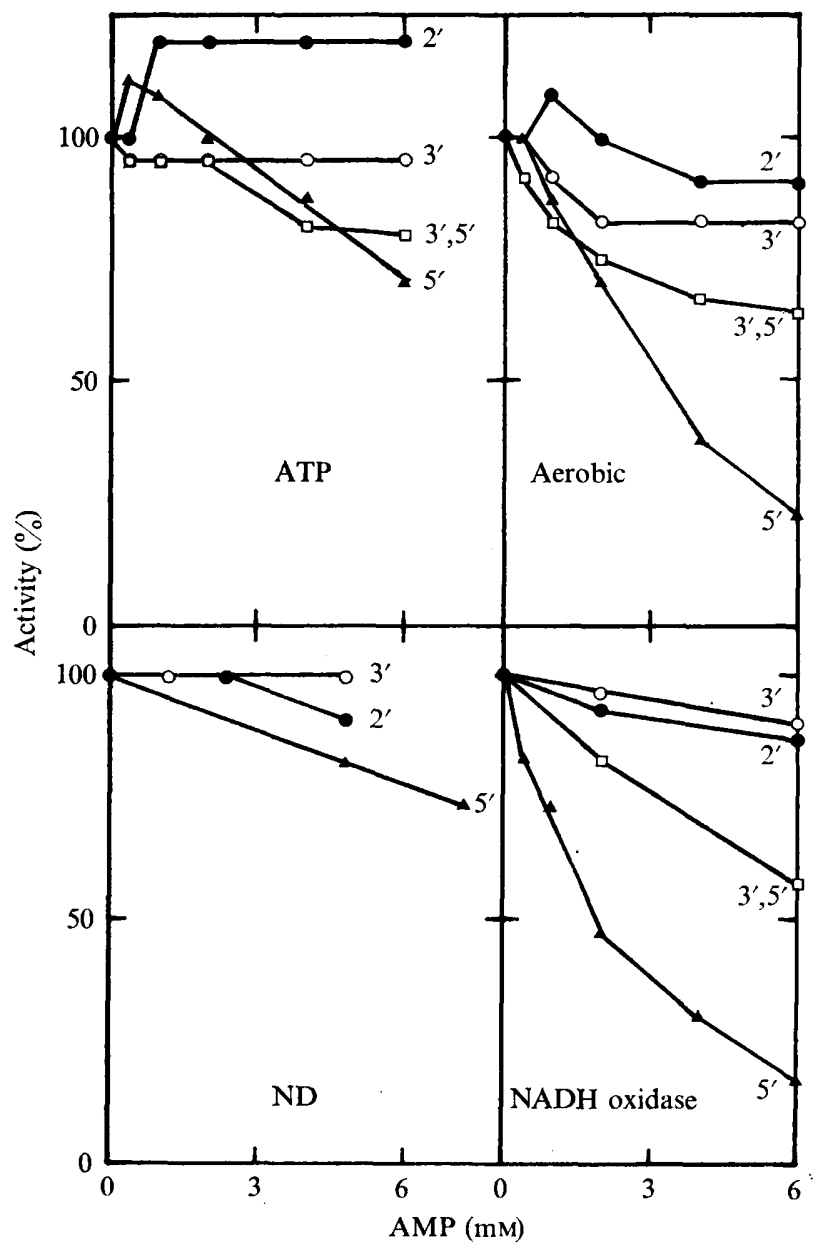

Fig. 2. Effect of adenosine $2^{\prime}-(0), 3^{\prime}-(0), 5^{\prime}-(\Delta)$ and $3^{\prime}, 5^{\prime}-(\square)$ phosphates on the aerobicdriven, ATP-driven, and energy-independent (ND) transhydrogenase activities and NADH oxidase activity of the particulate fraction from $S$. typhimurium. The specific activities of these enzymes in the absence of adenosine monophosphate were 17.6 to 24.1 , 18.9 to $29.5,135$, and 362 , respectively. The phosphates were incubated for $5 \mathrm{~min}$ at $37^{\circ} \mathrm{C}$ with the particulate fraction ( 1.5 to $2.2 \mathrm{mg}$ protein for energy-dependent and $0.48 \mathrm{mg}$ protein for energy-independent transhydrogenases, respectively; $0.48 \mathrm{mg}$ protein for NADH oxidase) before the reaction was started. The particulate fraction was prepared from cells grown on TS medium.

(Bragg \& Hou, 1972). The energized state can be coupled to the transhydrogenase enzyme (TH) to drive the energy-dependent transhydrogenation of NADP+ by NADH. The reverse reaction, the transhydrogenation of $\mathrm{NAD}^{+}$by $\mathrm{NADPH}$, does not require the energized state. Piericidin A, dicumarol, 3,3',5-tri-iodothyronine and 2,4-dinitrophenol inhibited all three transhydrogenase reactions (Table 3 ). This would be consistent with a site of action on the transhydrogenase enzyme, but it does not exclude further sites of inhibition elsewhere. Indeed with Escherichia coli, piericidin A and dicumarol inhibit the respiratory chain (Snoswell \& Cox, 1968; Bragg \& Hou, 1968).

CCCP inhibited the energy-dependent reactions but had no effect on the energyindependent transhydrogenase (Table 3); this compound presumably uncouples the 
Table 3. Effect of inhibitors on transhydrogenases of S. typhimurium

\begin{tabular}{|c|c|c|c|c|}
\hline \multirow[b]{2}{*}{ Inhibitor } & \multirow{2}{*}{$\begin{array}{l}\text { Concentration } \\
\text { (mM) }\end{array}$} & \multicolumn{3}{|c|}{ Transhydrogenase activity ( $\%)$} \\
\hline & & Independent & Aerobic-driven & ATP-driven \\
\hline None & - & $100^{*}$ & 100† & $100 \ddagger$ \\
\hline $3,3^{\prime}, 5^{\prime}$-Tri-iodothyronine & $\begin{array}{l}0.015 \\
0.030 \\
0.060 \\
0.120\end{array}$ & $\begin{array}{r}67 \\
44 \\
\text { N.D. } \\
\text { N.D. }\end{array}$ & $\begin{array}{r}79 \\
63 \\
37 \\
5\end{array}$ & $\begin{array}{l}84 \\
81 \\
45 \\
10\end{array}$ \\
\hline 2,4-Dinitrophenol & $\begin{array}{l}0.060 \\
0.119 \\
0.143\end{array}$ & $\begin{array}{c}\text { I06 } \\
\text { N.D. } \\
53\end{array}$ & $\begin{array}{r}100 \\
74 \\
\text { N.D. }\end{array}$ & $\begin{array}{l}\text { IIO } \\
\text { IOO } \\
\text { N.D. }\end{array}$ \\
\hline Dicumarol & $\begin{array}{l}0.077 \\
0.153\end{array}$ & $\begin{array}{r}111 \\
56\end{array}$ & $\begin{array}{l}90 \\
47\end{array}$ & $\begin{array}{r}103 \\
48\end{array}$ \\
\hline Piericidin A & $\begin{array}{l}0.060 \\
0.120\end{array}$ & $\begin{array}{c}\text { N.D. } \\
44\end{array}$ & $\begin{array}{l}74 \\
47\end{array}$ & $\begin{array}{r}100 \\
77\end{array}$ \\
\hline $\mathrm{CCCP}$ & $\begin{array}{l}0.013 \\
0.026\end{array}$ & $\begin{array}{l}160 \\
146\end{array}$ & $\begin{array}{r}37 \\
0\end{array}$ & $\begin{array}{r}16 \\
0\end{array}$ \\
\hline DCCD & $\begin{array}{l}0.042 \\
0.084 \\
0.126\end{array}$ & $\begin{array}{r}116 \\
103 \\
96\end{array}$ & $\begin{array}{r}103 \\
97 \\
88\end{array}$ & $\begin{array}{r}67 \\
19 \\
6\end{array}$ \\
\hline Phosphate & $8 \cdot 3$ & 135 & 100 & 23 \\
\hline Arsenate & $\begin{array}{r}5 \cdot 0 \\
10.0\end{array}$ & $\begin{array}{l}97 \\
96\end{array}$ & $\begin{array}{l}\text { II I } \\
\text { IOO }\end{array}$ & $\begin{array}{l}90 \\
74\end{array}$ \\
\hline $\mathbf{K C N}$ & $10 \cdot 0$ & 98 & 29 & 282 \\
\hline $\mathrm{Na}_{2} \mathrm{~S}$ & $5 \cdot 0$ & 90 & 58 & II 2 \\
\hline
\end{tabular}

The inhibitors were pre-incubated with the membrane particles for $5 \mathrm{~min}$ before the reaction was initiated. N.D., Not done.

* Specific activity, $9 \mathrm{I} \cdot 0$.

$\uparrow$ Specific activity, 9.0 (for DCCD experiment, 10.8).

¥ Specific activity, $14 \cdot 6$ (for DCCD experiment, $5 \cdot 0$ ).

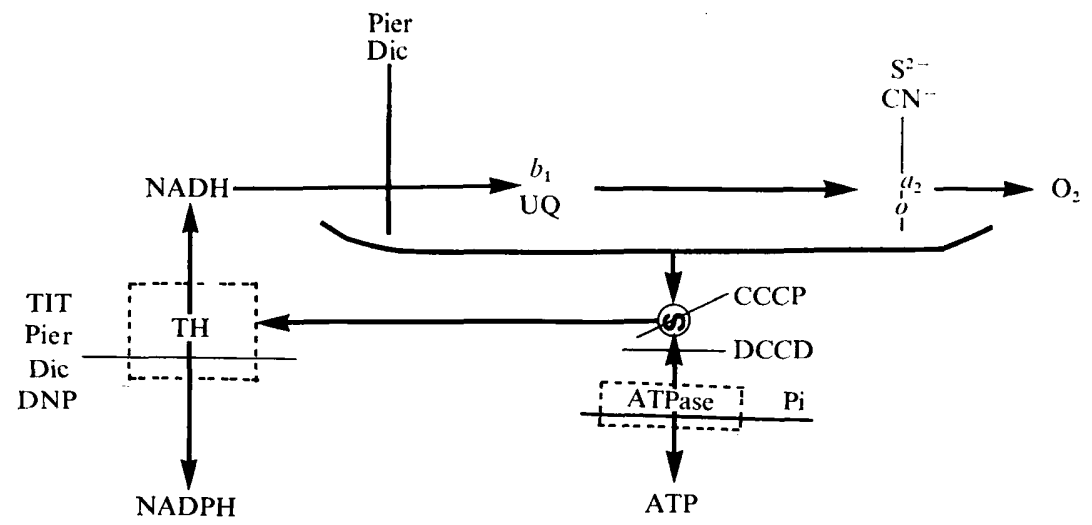

Fig. 3. Sites of action of inhibitors on the respiratory chain and transhydrogenase systems of $S$. typhimurium. TH, transhydrogenase enzyme; $\sim$, energized state; UQ, ubiquinone; $b_{1}, a_{2}, o$, cytochromes $b_{1}, a_{2}$, and $o$, respectively; TIT, 3,3',5-triiodothyronine; Pier, piericidin A; Dic, dicumarol; DNP, 2,4-dinitrophenol; DCCD, dicyclohexylcarbodiimide; Pi, phosphate. 


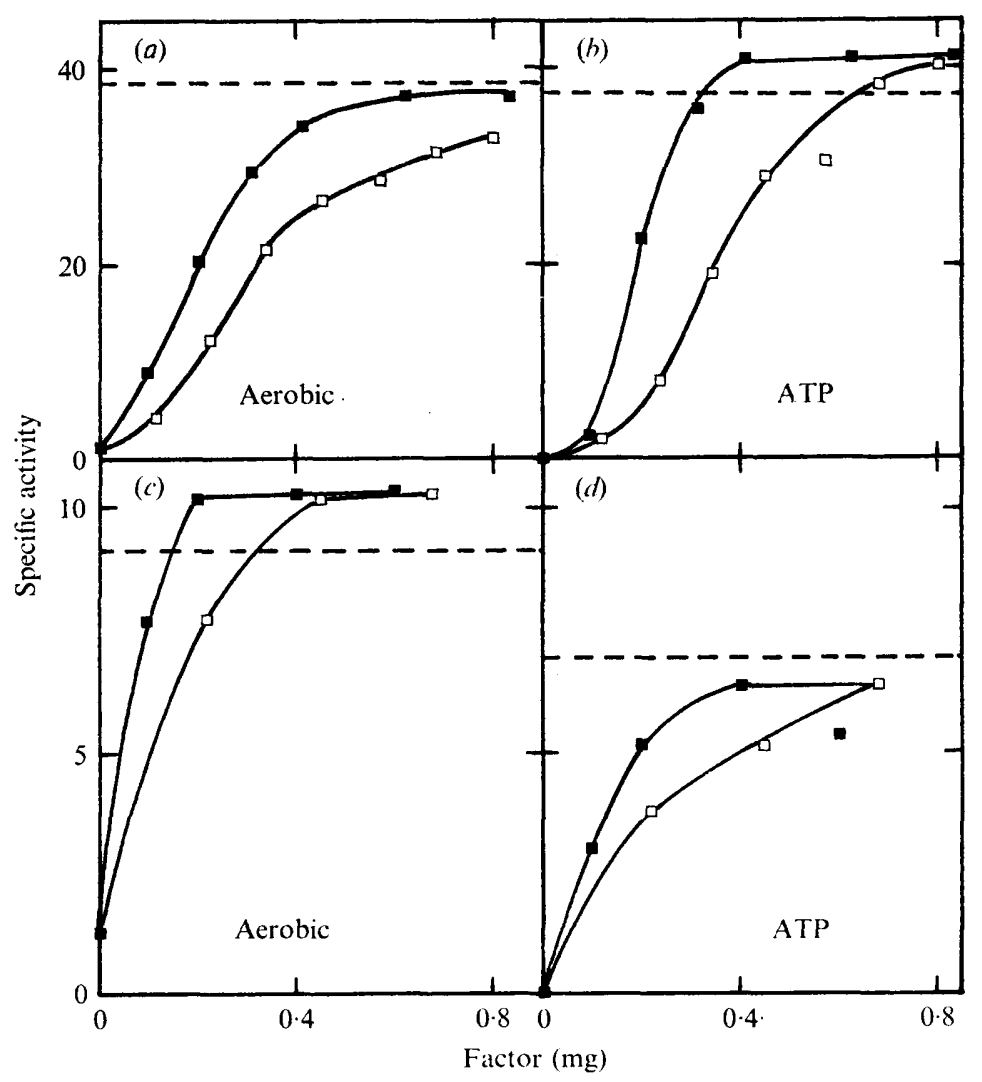

Fig. 4. Interchangeability of coupling factors prepared from E. coli ML308-225 and S. typhimurium. The aerobic- and ATP-driven transhydrogenase activities were assayed with stripped particulate fractions and coupling factors prepared as described in Methods. (a), (b) E. coli stripped particulate fraction (0.86 mg protein); (c), (d) $S$. typhimurium stripped particulate fraction (0.75 mg protein). 口, E. coli coupling factor; $\square, S$. typhimurium coupling factor. The coupling factor and stripped particulate fractions were incubated for $5 \mathrm{~min}$ at $37^{\circ} \mathrm{C}$ before the reaction was started. The broken line represents the specific activity in unstripped membrane preparations.

energy supply from the transhydrogenase enzyme. This view is consistent with its action on oxidative phosphorylation in mitochondria (Heytler, 1963).

DCCD inhibited the ATP-driven but not the aerobic-driven or energy-independent transhydrogenase activities (Table 3). Thus, DCCD must act at a reaction step between ATP and the energized state as shown in Fig. 3. It is probably not acting on the ATPase itself, since it can exert an effect on the transhydrogenase reaction in membrane particles which have been depleted of the ATPase (Bragg \& Hou, I973).

The inhibition of the ATP-driven transhydrogenase reaction by phosphate, and the absence of an effect on the aerobic-driven and energy-independent reactions, suggests that the ATPase is inhibited (Roisin \& Keeps, 1972) rather than the transhydrogenase. This is in contrast to the soluble transhydrogenases of Pseudomonas fluorescens (Kaplan, Colowick \& Neufeld, 1952) and Azotobacter vinelandii (Chung, 1970) which are inhibited directly by phosphate.

The aerobic-driven transhydrogenase activity was inhibited by sulphide and by cyanide, but these agents had no effect on energy-independent or ATP-driven reactions (Table 3). 
These compounds, like $5^{\prime}$-AMP, primarily act on the respiratory chain and so interfere with the aerobic generation of the energized state.

No marked differences were noticed in the effect of the above inhibitors on the transhydrogenase systems of Escherichia coli and Salmonella typhimurium, suggesting that the transhydrogenase enzyme is similar in these two organisms. This view is further supported by the interchangeability of the coupling factor ATPase of these two bacteria (Fig. 4). Dialysis of the particulate fraction from S. typhimurium resulted in the loss of both aerobicand ATP-driven transhydrogenase activities, which could be fully restored by the addition of a coupling factor preparation from either S. typhimurium or E. coli (Fig. 4). The coupling factor from $S$. typhimurium was also fully able to restore the energy-dependent transhydrogenase activities in factor-depleted particles from $E$. coli. This result is of interest in the light of the failure of the transhydrogenase factor of Rhodopseudomonas spheroides to cross-react with the Rhodospirillum rubrum system (Konings \& Guillory, 1972). Furthermore, these results suggest that $S$. typhimurium has a $\mathrm{Ca}^{2+}, \mathrm{Mg}^{2+}$-activated ATPase which is similar in structure and function to that of $E$. coli.

The results presented in this paper do not explain the differences in the response of the aerobic-driven transhydrogenase systems of Escherichia coli and Salmonella typhimurium to the presence of amino acids in the growth medium. However, it is unlikely that this is due to any fundamental difference between the two-transhydrogenase systems.

This investigation was supported by a grant from the Medical Research Council of Canada.

\section{REFERENCES}

BragG, P. D., Davies, P. L. \& Hou, C. (1972). Function of energy-dependent transhydrogenase in Escherichia coli. Biochemical and Biophysical Research Communications 47, $1248-1255$.

BragG, P. D. \& Hou, C. (I968). Oxidative phosphorylation in Escherichia coli. Canadian Journal of Biochemistry 46, 63I-64I.

BragG, P. D. \& Hou, C. (1972). Purification of a factor for both aerobic-driven and ATP-driven energydependent transhydrogenases of Escherichia coli. FEBS Letters 28, 309-312.

BraGG, P. D. \& Hou, C. (1973). Reconstitution of energy-dependent transhydrogenase in ATPase-negative mutants of Escherichia coli. Biochemical and Biophysical Research Communications 50, 729-736.

Chung, A. E. (1970). Pyridine nucleotide transhydrogenase from Azotobacter vinelandii. Journal of Bacteriology ro2, 438-447.

Cohen, P. T. \& KaPlan, N. O. (1970). Purification and properties of the pyridine nucleotide transhydrogenase from Pseudomonas aeruginosa. Journal of Biological Chemistry 245, 2825-2836.

Davies, P. L. \& Bragg, P. D. (1972). Properties of a soluble $\mathrm{Ca}^{2+}$ - and $\mathrm{Mg}^{2+}$-activated ATPase released from Escherichia coli membranes. Biochimica et biophysica acta 266, 273-284.

Fisher, R. J. \& SANADI, D. R. (197I). Energy-linked nicotinamide adenine dinucleotide transhydrogenase in membrane particles from Escherichia coli. Biochimica et biophysica acta 245, 34-4I.

HeYtLER, P. G. (1963). Uncoupling of oxidative phosphorylation by carbonylcyanide phenylhydrazones. I. Some characteristics of $m-\mathrm{Cl}-\mathrm{CCP}$ action on mitochondria and chloroplasts. Biochemistry $2,35 \mathrm{I}-$ $36 \mathrm{I}$.

HoNG, J. S. \& KABACK, H. R. (1972). Mutants of Salmonella typhimurium and Escherichia coli pleiotropically defective in active transport. Proceedings of the National Academy of Sciences of the United States of America 69, 3336-3340.

Imai, K., Iijima, T. \& Hasegawa, T. (1973). Transport of tricarboxylic acids in Salmonella typhimurium. Journal of Bacteriology II4, 96I-965.

KaPLAN, N. O. (1967). Beef-heart TPNH-DPN pyridine nucleotide transhydrogenases. In Methods in Enzymology, vol. 10, pp. 317-322. Edited by R. W. Estabrook and M. E. Pullman. New York: Academic Press.

Kaplan, N. O., Colowick, S. P. \& Neufeld, E. F. (1952). Pyridine nucleotide transhydrogenase. II. Direct evidence for and mechanism of the transhydrogenase reaction. Journal of Biological Chemistry I95, 107-I 19. 
KaWASAKI, T., SATOH, K. \& KAPLAN, N. O. (1964). The involvement of pyridine nucleotide transhydrogenase in ATP-linked TPN reduction by DPNH. Biochemical and Biophysical Research Communications $17,648-654$.

KonINGs, A. W. T. \& GuILLORY, R. J. (1972). Specificity of the transhydrogenase factor for chromatophores of Rhodopseudomonas spheroides and Rhodospirillum rubrum. Biochimica et biophysica acta 283, 334338.

Lee, C. P., Simard-Duquesne, N., Ernster, L. \& Hoberman, H. D. (1965). Stereochemistry of hydrogentransfer in the energy-linked pyridine nucleotide transhydrogenase and related reactions. Biochimica et biophysica acta 105, 397-409.

Lowry, O. H., Rosebrough, N. J., Farr, A. L. \& Randall, R. J. (195I). Protein measurement with the Folin phenol reagent. Journal of Biological Chemistry 193, 265-275.

REvSIN, B. \& BRODIE, A. F. (1967). An effect of inorganic phosphate and AMP at the third phosphorylation site of the respiratory chain of Mycobacterium phlei. Biochemical and Biophysical Research Communications $28,635-640$.

RoIsIN, M. P. \& KePES, A. (1972). The membrane ATPase of Escherichia coli. I. Ion dependence and ATPADP exchange reaction. Biochimica et biophysica acta 275, 333-346.

RYDSTRöM, J. (1972). Site-specific inhibitors of mitochondrial nicotinamide-nucleotide transhydrogenase. European Journal of Biochemistry 31, 496-504.

Simoni, R. D. \& Shallenberger, M. K. (1972). Coupling of energy to active transport of amino acids in Escherichia coli. Proceedings of the National Academy of Sciences of the United States of America 69 , 2663-2667.

Snoswell, A. M. \& Cox, G. B. (1968). Piericidin A and inhibition of respiratory chain activity in Escherichia coli K12. Biochimica et biophysica acta 162, 455-458.

SWEETMAN, A. J. \& GrIFFTTHS, D. E. (197I). Studies of energy-linked reactions. Energy-linked transhydrogenase reaction in Escherichia coli. Biochemical Journal 121, I25-130.

Van den Broek, H. W. J., Santema, T. S., Wassink, J. H. \& Veeger, C. (I971). Pyridine-nucleotide transhydrogenase. I. Isolation, purification, and characterization of the transhydrogenase from Azotobacter vinelandii. European Journal of Biochemistry 24, 31-45.

WorCEL, A. \& Goldman, D. S. (1964). Activation by AMP of the NADH oxidase of Mycobacterium tuberculosis. Biochemical and Biophysical Research Communications 17, 559-564. 